\title{
PERANCANGAN SISTEM INFORMASI EKSTRAKURIKULER TAEKWONDO DI SDN KRAMAT JATI 18
}

\author{
Suti Alawiyah', Tri Yani Akhirina ${ }^{2}$, Nurfidah Dwitiyanti ${ }^{3}$ \\ Program Studi Teknik Informatika, Fakultas Teknik dan Ilmu Komputer, \\ Universitas Indraprasta PGRI \\ Jalan Raya Tengah No 80, Kelurahan Gedong, Pasar Rebo, Jakarta Timur \\ salawiyah4@gmail.com¹, azizahputriku@gmail.com², nurfidah.pulungan@gmail.com³
}

\begin{abstract}
Abstrak
Teknologi informasi merupakan salah satu faktor pendukung utama yang dapat mempermudah sebuah pekerjaan. Berkembangnya teknologi informasi pada semua jenis bidang salah satunya pada bidang pendidikan yaitu dengan membuat sekolah memanfaatkan teknologi informasi untuk memudahkan kinjera sekolah, khususnya pada saat pendataan dan penilaian anggota ekstrakurikuler taekwondo. Tujuan penelitian ini untuk mempermudah pendataan dan penilaian ekstrakurikuler menjadi lebih cepat, efektif dan efisien. Sistem Informasi Ekstrakurikuler Taekwondo di SDN Kramat Jati 18 Sebelumnya masih menggunakan tulisan tangan dalam pendataan dan penilaian ekstrakurikuler yaitu menggunakan buku, sehingga pelatih yang bersangkutan akan mengalami kesulitan saat mencari data dari beberapa tumpukan data anggota ekstrakurikuler. Dalam menyelesaikan masalah tersebut peneliti menggunakan metode Research and Development (R\&D) pada sistem terkomputerisasi menggunakan penelitian berbasis desktop dengan Java. Penelitian dilakukan di SDN Kramat Jati 18, aplikasi yang dikerjakan mampu mengolah sistem informasi pendataan dan penilaian ekstrakurikuler menjadi lebih cepat, efektif, efisien dan mampu menyelesaikan permasalahan yang ada.
\end{abstract}

Kata Kunci: perancangan, sistem informasi, taekwondo, java, desktop.

\begin{abstract}
Information technology is one of the main supporting factors that can facilitate a job. The development of information technology in all types of fields one of them in the field of education is to make schools use information technology to facilitate school kinjera, especially during the collection and assessment of taekwondo extracurricular members. The purpose of this study is to make it easier for extracurricular data collection and assessment to be faster, effective and efficient. Taekwondo Extracurricular Information System at SDN Kramat Jati 18 Previously still uses handwriting in extracurricular data collection and assessment that uses books, so that the coach concerned will have difficulty when searching for data from several piles of extracurricular member data. In solving this problem, the researcher used research and development $(R \& D)$ methods on computerized systems using desktop-based research with Java. The research was conducted at SDN Kramat Jati 18, the application carried out was able to process data collection information systems and extracurricular assessments to be faster, effective, efficient and able to solve existing problems.
\end{abstract}

Keyword: designing, information system, taekwondo, java, deskop.

\section{PENDAHULUAN}

Teknologi informasi merupakah salah satu faktor pendukung utama yang dapat mempermudah sebuah pekerjaan menjadi lebih cepat, ekonomis, akurat dan lebih terjaga keamanannya. Salah satu yang berkembang pada saat ini adalah komputer. Dengan menggunakan komputer tidak perlu lagi menghitung dan menganalisa data secara manual, selain itu data atau informasi yang diperoleh dri komputer lebih cepat dan akurat dengan perancangan suatu sistem. Perancangan merupakan proses pengembangan spesifikasi baru berdasarkan rekomendasi hasil analisis sistem (Subhan, 2012), sedangkan Sistem adalah sekumpulan elemen yang saling terkait atau terpadu yang dimaksudkan untuk mencapat suatu tujuan menurut (Kadir, 2014). Informasi menurut (Hartono, 2013) adalah data yang sudah diolah menjadi sebuah bentuk yang berguna dan nyata atau berupa nilai yang dapat dipahami oleh penerima informasi sehingga dapat digunakan menjadi sebuah keputusan 
sekarang maupun yang akan datang. Berkembangnya teknologi informasi pada semua jenis bidang salah satunya pada bidang pendidikan yaitu dengan membuat sekolah memanfaatkan teknologi informasi untuk memudahkan kinerja sekolah, khususnya pada saat pendataan dan penilaian anggota ekstrakurikuler taekwondo.

Berdasarkan latar belakang di atas maka rumusan masalahnya adalah bagaimana membuat perancangan sistem informasi yang efektif dan efisien dalam penginputan data anggota, data pelatih dan data penjadwalan latihan pada ekstrakurikuler taekwondo Sdn Kramat Jati 18, bagaimana membuat proses penilaian anggota ekstrakurikuler taekwondo di Sdn Kramat Jati 18 agar efektif dan efisien serta lebih baik dari sebelumnya.

Manfaat yang didapat dari hasil penelitian ini adalah mempermudah pelatih pada saat penginputan data-data menjadi lebih cepat, efektif dan efisien, pelatih dapat membuat laporan penilaian anggota yang lebih rinci untuk melihat perkembangan dari anggota ekstrakurikuler taekwondo.

\section{PENELITIAN RELEVAN}

Peneliti melakukan penelusuran terhadap (Fajar, 2016) yang mampu membuat sistem informasi untuk menyimpan seluruh data pada ekstrakurikuler taekwondo dalam suatu database serta mempermudah admin dan masyarakat umum untuk mengakses sistem tersebut. Selain itu peneliti juga mengacu pada (Rivaldi, 2017) yang membuat sistem pengolahan obat berbasis java untuk mempermudah pekerjaan user dalam memproses data dan akan memberikan kepuasan terhadap Iuser Idalam bertransaksi mengolah data. Selain itu peneliti juga mengacu pada (Karno\&Wicaksono, 2016) yang membuat sistem informasi penilaian siswa ekstrakurikuler menggunakan visual basic yang dapat membantu admin dalam memasukan data dan menampilkan informasi yang berkaitan dengan input data siswa, pelatih, jadwal, pengembangan diri dan penilaian yang bisa langsung dicetak.dari ketiga penelitian tersebut dapat ditemukan persamaan seperti tujuan pembuatan untuk mempermudah admin dalam mengolah seluruh data agar lebih cepat, efisien dan efektif. Selain persamaan terdapat juga perbedaan dalam penelitian yang saya lakukan yaitu penelitian tersebut bisa dilakukan secara online dan bisa diakses banyak orang.

\section{METODE PENELITIAN}

Dalam penelitianini peneliti menggunakan metode penelitian Research and Development (R\&D). Menurut (Sugiyono, 2016) Metode R\&D adalah metode penelitian yang digunakan untuk menghasilkan produk tertentu dan menguji keefektifan produk tertentu. Sedangkan Putra (Putra, 2011) menyatakan bahwa metode penelitian secara sengaja, sistematis, untuk menemukan, memperbaiki, mengambangkan, menghasilkan, maupun menguji keefektifan produk, model, maupun metode/strategi/cara yang lebih unggul, baru, efektif, efieisen, produktif dan bernakna. Dapat disimpulkan bahwa Research and Development (R\&D) adalah suatu teknik atau metode mencari suatu produk, memperoleh, mengumpulkan atau mencatat produk yang digunakan untuk keperluan dan faktor-faktor yang berhubungan dengan pokok permasalahan sehingga akan didapat suatu kebenaran atas produk yang diperoleh. Proses pengujian produk dengan menggunakan penelitian eksperimen yang disebut dengan penelitian terapan (Applied Research). Adapun langkah - langkah dalam penelitian adalah sebagai berikut:

a. Potensi dari Masalah

Potensi adalah segala sesuatu yang bila didayagunakan akan memiliki nilai tambah. Masalah adalah penyimpanan antara yang diharapkan dengan yang terjadi.

b. Mengumpulkan Informasi

Mengumpulkan informasi digunakan sebagai bahan untuk perencanaan produk tertentu yang diharapkan dapat mengatasi masalah tersebut.

c. Desain Produk

Produk didesain untuk dapat mengatasi masalah yang ada.

d. Validasi Desain 
Validasi desainmerupakan kegiatan penilaian rancangan produk oleh ahli yang berkompeten dibidangnya.

e. Perbaikan Desain

Setelah desain produk, dinilaimelalui diskusi dengan pakar dan para ahli lainnya, maka akan dapat dikeahui kelemahannya. Kelemahan tersebut dikurangi dengan memperbaiki desain.

f. Uji Coba Produk

Produk diujicobakan pada kelompok terbatas.

g. Revisi Produk

Kelemahan - kelemahan produk yang ditemukan dalam sampel terbatas selanjutnya diperbaiki untuk memperoleh produk yang lebih sempurna.

h. Uji Coba Pemakaian

Produk diujiacobakan pada kelompok yang lebih luas

i. Revisi Produk

Perbaikan produk apabila ditemukan kelemahan pada uji coba skala luas.

j. Pembuatan Produk Masal

Produk final yang dihasilkan diproduksi secara masal untuk dapat digunakan secara optimal.

\section{HASIL DAN PEMBAHASAN}

Data flow diagram atau dalam bahasa Indonesia adalah Diagram Alir Data (DAD) yang merupakan model dari sistem untuk menggambarkan pembagian sistem ke modul yang lebih besar (Ladjamudin, 2013). Sedangkan menurut Pressman dalam (Rita, 2014) yaitu obyek-obyek data mengalir ke dalam perangkat lunak, kemudian ditransformasi oleh elemen-elemen pemrosesan, dan obyek-obyek data hasilnya akan mengalir keluar dari sistem/perangkat lunak. Maka dapat disimpulkan bahwa diagram alir data (DAD) adalah diagram yang menggambarkan pembagian suatu sistem pada aliran perangkat lunak.

Berikut ini adalah diagram alir data dari diagram konteks sistem berjalan :

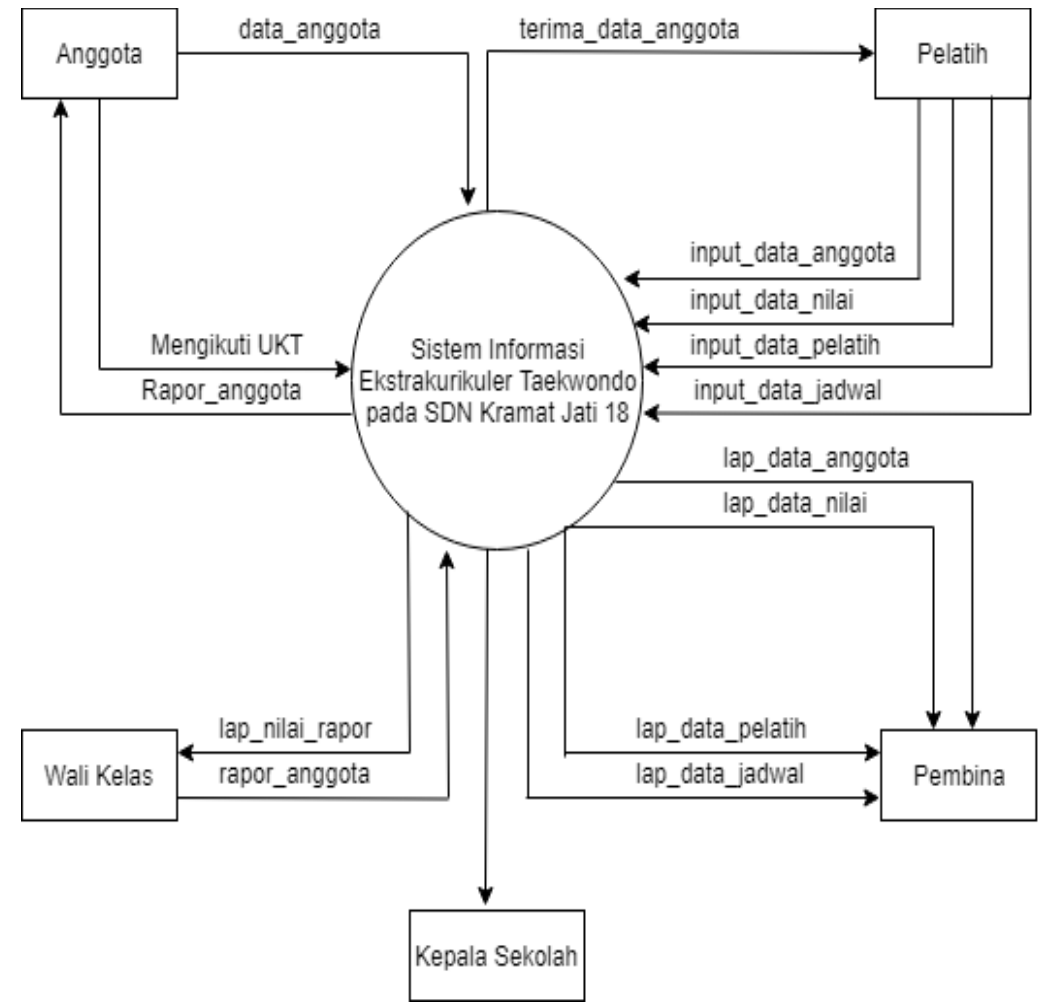

Gambar 1. Diagram Konteks Sistem Berjalan 
Analisis permasalahan yang dapat disimpulkan dari hasil penelitian pada Ekstrakurikuler Taekwondo SDN Kramat Jati 18 bahwa eskul ini masih menggunakan sistem data yang manual sehingga kurang efisien dalam waktu, biaya dan pengerjaan laporan dikarenakan lamanya dalam pencarian data dalam buku catatan. Kesalahan data bisa dilihat dari kerusakan data, hilangnya data, kesalahan dalam perhitungan nilai karena semua dibuat dengan manual, sehingga data laporan serta informasi yang disajikan masih kurang akurat. Alternatif penyelesaian masalah yang peneliti usulkan dengan perancangan sistem informasi yang dapat membantu mengatasi kekurangan yang ada dan dapat menghasilkan informasi serta laporan yang cepat dan tepat. Perancangan sistem informasi ekstrakurikuler taekwondo di SDN Kramat Jati 18 dibangun dengan menggunakan bahasa pemrograman Jawa Netbeans dengan menggunakan Database MySQL.

Berikut ini adalah gambaran diagram alir data sistem yang diusulkan pada Ekstrakurikuler Taekwondo SDN Kramat Jati 18 adalah sebagai berikut :

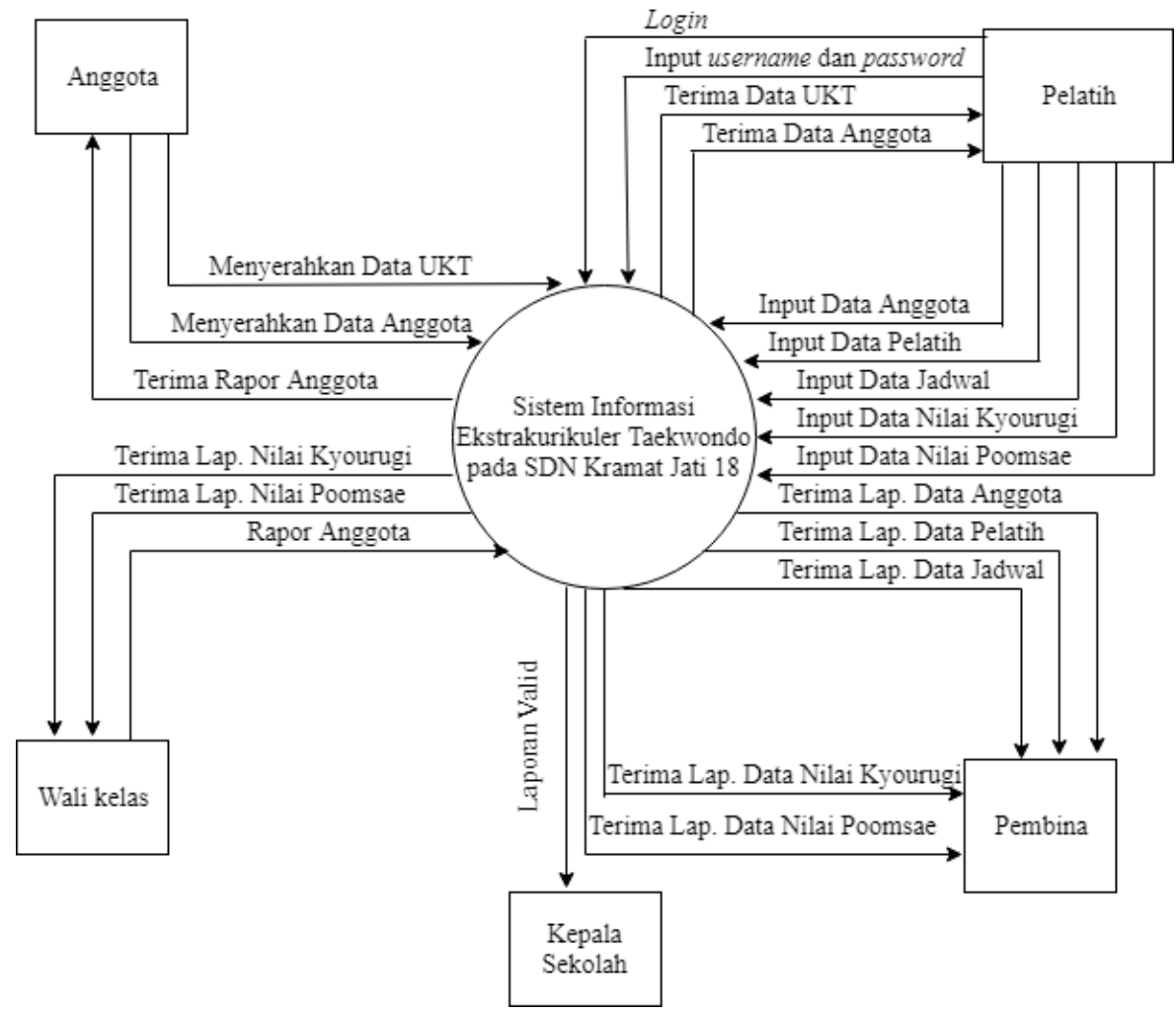

Gambar 2. Diagram Konteks Sistem yang Diusulkan

Peneliti membuat aplikasi ini dengan menggunakan java netbeans edisi 8.2 dengan database MySQL aplikasi Xampp. Berikut tampilan aplikasi pada Sistem Informasi Ekstrakurikuler Taekwondo di SDN Kramat Jati 18 : 


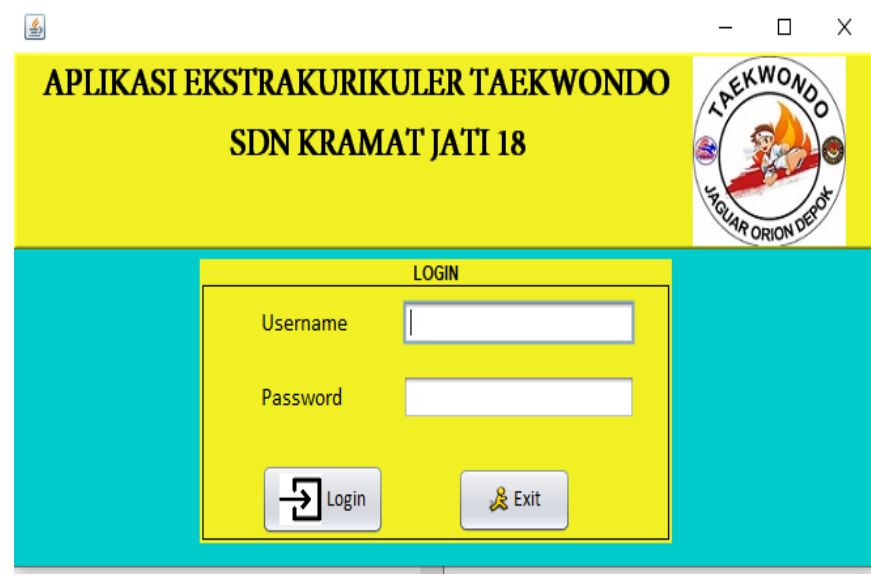

Gambar 3. Tampilan Layar Login

Untuk masuk ke menu utama, user harus melakukan login terlebih dahulu agar bisa mengakses sistem tersebut. Ketika user dalam memasukkan username atau password, diharapkan untuk mengecek kembali apakah username dan password sudah terisi dengan benar.

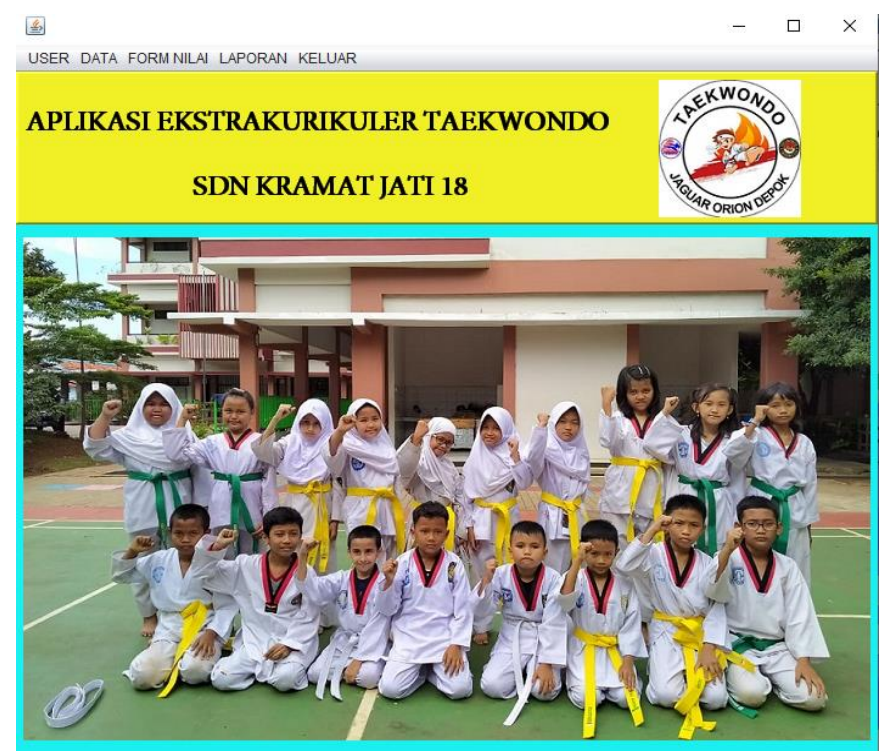

Gambar 4. Tampilan Menu Utama

Menu utama berisi tombol user, data, form nilai, laporan dan keluar. Menu - menu tersebut memiliki submenu yang berisi data anggota, data pelatih, data jadwal, form kyourugi, form poomsae, laporan data anggota, laporan data pelatih, laporan data jadwal, laporan nilai kyourugi, dan laporan nilai poomsae. Ketika salah satu button ditekan, maka akan menuju ke form selanjutnya yang dipilih oleh user.

Berikut ini adalah hasil keluaran (printout) yang nanti hasilnya dapat menjadi laporan manual kepada anggota, pembina, wali kelas dan kepala sekolah. 


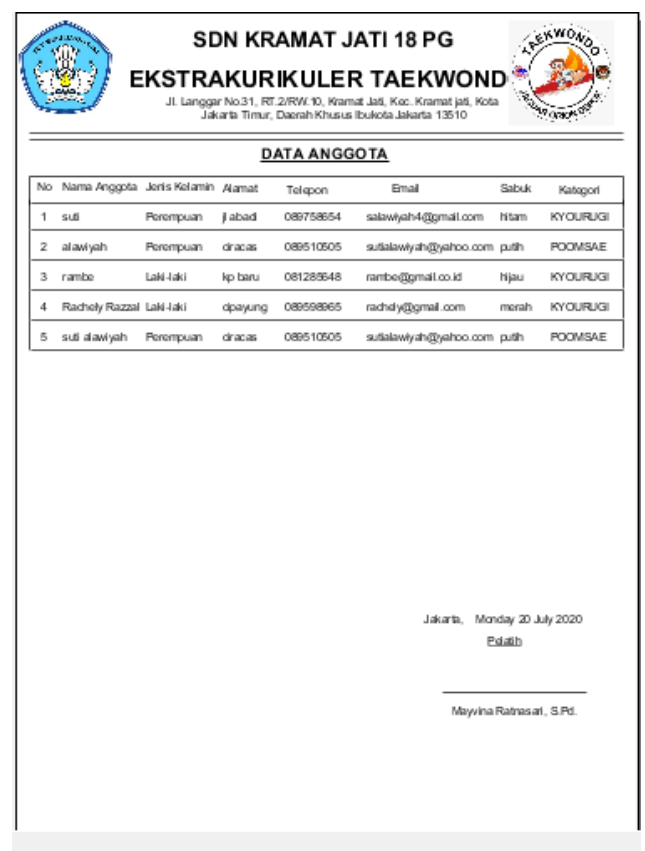

Gambar 5. Tampilan Laporan Hasil Data Anggota

Tampilan laporan data anggota berisi data anggota aktif taekwondo yang dibuat setiap satu semester. Selanjutnya laporan ini akan di berikan kepada pembina dan pembina memberikan kepada kepala sekolah.

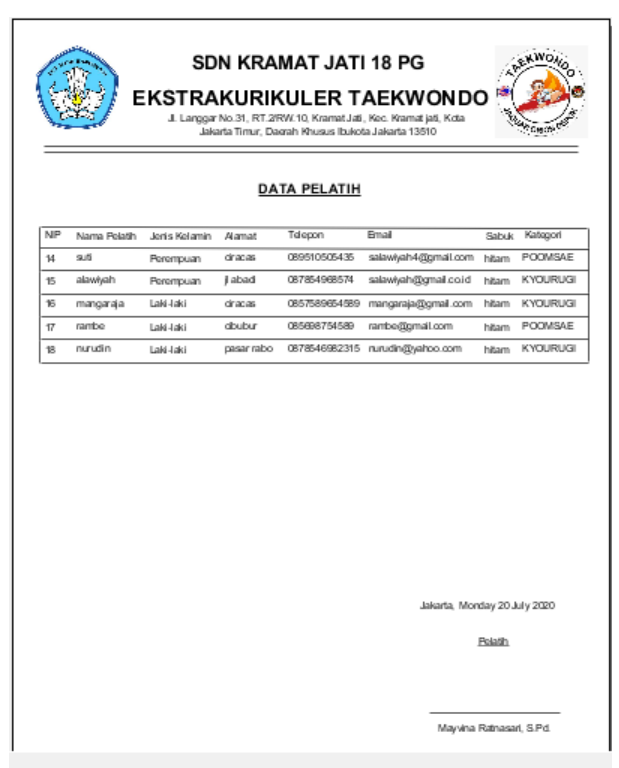

Gambar 6. Tampilan Laporan Hasil Data Pelatih

Tampilan laporan data pelatih berisi data pelatih aktif yang dubuat setiap satu semester. Selanjutnya laporan ini akan di berikan kepada pembina dan pembina memberikan kepada kepala sekolah. 


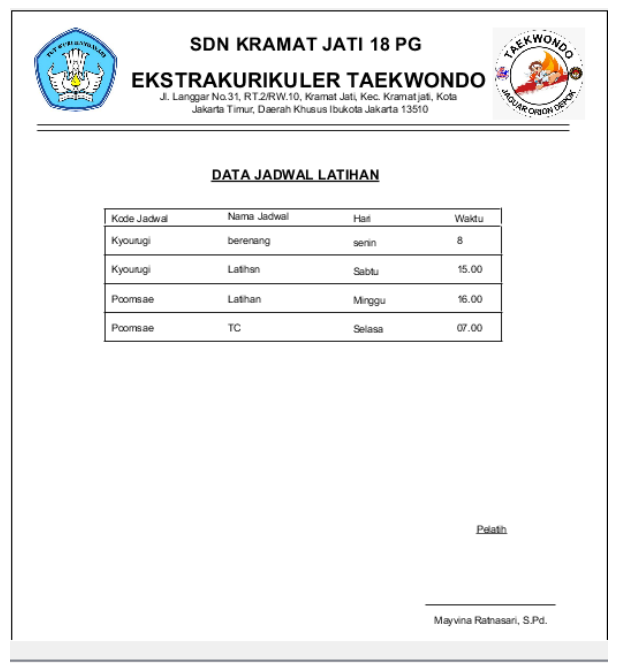

Gambar 7. Tampilan Laporan Hasil Data Jadwal

Tampilan laporan data jadwal berisi data jadwal Latihan taekwondo yang dibuat setiap satu semester. Selanjutnya laporan ini akan di berikan kepada pembina dan pembina memberikan kepada kepala sekolah.

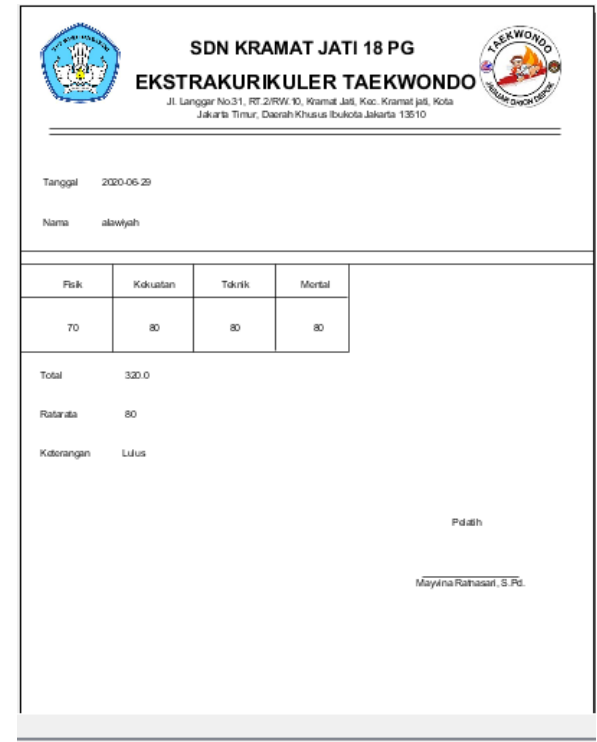

Gambar 8. Tampilan Laporan Hasil Nilai Kyourugi

Tampilan laporan nilai kyourugi berisi nilai anggota kyourugi perorangan yang dibuat setiap ujian kenaikan tingkat (UKT). Selanjutnya laporan ini akan di berikan kepada pembina, pembina memberikan kepda wali kelas, lalu wali kelas memberikan kepada anggota taekwondo dan memnerikan kepada kepala sekolah. 


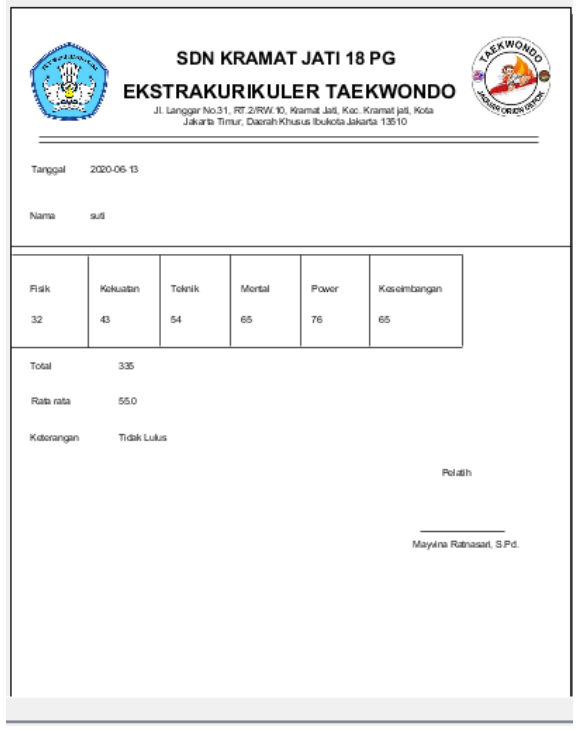

Gambar 9. Tampilan Laporan Hasil Nilai Poomsae

Tampilan laporan nilai poomsae berisi nilai anggota poomsae perorangan yang dibuat setiap ujian kenaikan tingkat (UKT). Selanjutnya laporan ini akan di berikan kepada pembina, pembina memberikan kepda wali kelas, lalu wali kelas memberikan kepada anggota taekwondo dan memnerikan kepada kepala sekolah.

\section{SIMPULAN}

Berdasarkan hasil penelitian yang dilakukan di Ekstrakurikuler Taekwondo SDN Kramat Jati 18, peneliti dapat simpulkan dengan menggunakan system komputerisasi maka Ekstrakurikuler Taekwondo dapat mempermudah keberhasilan dalam pengelolaan, khususnya untuk membantu dalam menata pengelolaan data agar lebih efisien dan efektif. Pembuatan system informasi ini dapat meningkatkan laporan menjadi lebih cepat dan akurat, sehingga mengurangi resiko duplikasi data.

\section{DAFTAR PUSTAKA}

Afyenni, R. 2014. (2014). Perancangan Data Flow Diagram untuk Sistem Informasi Sekolah (Studi Kasus Pada SMA Pembangunan Laboratorium UNP). Teknoif, 2(1), 35-39.

Fajar, A. S. (2016). Perancangan Sistem Pemantauan Anggota Ekstrakurikuler Taekwondo di MTS Salafiyah Syafi'iyyah Pangkalan Jati.

Hartono, B. (2013). Sistem Informasi Manajemen Berbasis Komputer. PT. Rineka Cipta.

Kadir, A. (2014). Pengenalan Sistem Informasi Edisi Revisi. Andi Offset.

Karno, H. W., \& Wicaksono, T. A. (2016). Sistem Informasi Penilaian Siswa Ekstrakurikuler Menggunakan Visual Basic 6.0 Pada SMA Negeri 1 Bojong. 2(1), 50-56.

Ladjamudin, A.-B. Bin. (2013). Analisa dan Desain Sistem Informasi. Graha Ilmu.

Putra, N. (2011). Research and Development Penelitian dan Pengembangan. PT. RAJAGRAFINDO PERSADA.

Rivaldi, A. A. (2017). Perancangan Sistem Informasi Aplikasi Pengelolaan Obat Berbasis Java Pada PT Indofarma $T B K$.

Subhan, M. (2012). Analisa Perancangan Sistem. Lentera Ilmu Cendekia.

Sugiyono. (2016). Metode Penelitian Kuantitatif, Kualitatif, dan R\&D. PT. Alfabet. 